\title{
The Accepted “Clinical Interaction Model”: A Special Case of Reality
}

\section{Kristiansen $\mathrm{JEH}^{1 *}$ and Fey $\mathbf{S} \mathrm{J}^{2}$}

${ }^{1}$ Center for Biomembrane Physics (Memphys), University of Southern Denmark, Campusvej 55, DK-5230, Odense M, Denmark

${ }^{2}$ Department of Biochemistry and Molecular Biology, University of Southern Denmark, Campusvej 55, DK-5230, Odense M, Denmark

\begin{abstract}
Pharmacology has focussed on the effects of compounds on tissues and organs with a view to promoting the well-being of a patient. This has been a special case of 'reality'. With the dual realisation that these compounds can also have effects on microorganisms living in and on the patient and that these microorganisms play a vital role in maintaining the health of the patient it is essential that we modify our perspective to include the host, the microorganisms and compounds that affect either into a general theory for pharmacology.
\end{abstract}

Keywords: Pharmacology; Microorganisms; Psychotherapeutic drugs; Antibiotic

\section{Opinion}

Over a hundred years ago, Poul Ehrlich (1854-1915) proposed a lock and key model for the interaction between drug and target in which a ligand fits into a 3-dimension pocket [1]. For many years, this was a source of inspiration and dovetailed well with the reductionist approach of science. This led to the development of in vitro high-throughput screening and the construction of massive combinatorial chemistry libraries. The initial lock and key concept has been modified several times to include ligand and target flexibility (leading to the hand in glove analogy). Theoretically, a highly specific treatment should be better tolerated due to an absence of off-target side effects. Unfortunately, practice has shown that there is a poor correlation between in vitro drug effects and in vivo efficacy with target-driven approximations [2,3]. Our increasing understanding of the multiple interacting feedback mechanisms operating within the cell has led to the realization that polypharmacology (the interaction of a single drug on multiple targets or the use of multiple drugs on multiple targets) will be necessary to treat the majority of non-monogenic disorders [4-7].

But there is another level of complexity that is equally important and also needs to be considered. Generally speaking, in the development of drugs, the demands are for as high a degree of "medical resolving problems" and as few negative side effects as possible.

For the sake of this discussion, let drugs be divided into two groups: Parasitotropic and organotropic. In this article, we will use the Oxford Dictionary definition of parasite "An organism that lives on, in, or with an organism of another species, obtaining food, shelter, or other benefit". We naturally attach a negative stigma to the word 'parasite' but in the case of the gut microbiota we owe them an apology. An alternative word would be a "mutualist"-an organism which gives a quid pro quo or specific beneficial service to the host which affords it sustenance and domicile (definition adapted from American Naturalist vol. 28, p: 713, 1894).

Parasitotropic-directed drugs, such as antibiotics and chemotherapeutic agents, are developed with aim of exploiting their antimicrobial characteristics, while making every effort to limit their negative side effects on the patient host (human and/or animal). Here, possible positive side effects on the host are neglected.

Organotropic-drugs, on the other hand, are in general developed without any considerations for their possible effects on microorganisms. The focus is on obtaining a beneficial effect on the patient.
The importance of microorganisms for human health is only just beginning to be realised: about half of the cells and only $1 \%$ of the genes found in our bodies are human [8]. The gut microbiota has been called the 'hidden organ' because it has been overlooked for so long. It is essential for the maintenance of health, behaviour and learning. The microbiota is also involved in metabolising exogenous compounds (e.g. food and medicines), thus significantly affecting drug pharmacokinetics (bioavailability, efficacy and adverse effects) [9]. It is becoming increasingly recognised for its influences on several diseases including obesity, and diabetes [10] and microbial dysbiosis is being linked to autism, depression, Alzheimer's and Parkinson's diseases $[8,11]$.

Considering the various roles of microrganisms in our gut, the current approach to drug discovery is thus incomplete. Clinical studies are the first opportunity to 'observe' this, and the high rejection rate of candidate drugs may be one of the consequences of this oversight.

Evidence that compounds having both parasitotropic directed and organotropic directed activities have existed in the literature for many years but have been ignored. One of the earliest examples, was methylene blue (a phenothiazine) which has both antimalarial, painkilling and neuroleptic activity [12-15].

In our investigations and in the historical studies we have now been able to confirm that neurotropics (especially psychotherapeutic drugs in general) and their analogues have antimicrobial effects in vitro and in vivo [16-20].

These drugs and other compounds having both organotropic directed and parasitotropic directed activities are called 'non-antibiotics' [21]. Clinically, the parasitotropic effect of the organotropic drugs is generally ignored, and, for all intents and purposes, the possibility for both negative and positive side effects have been neglected. This biologically 'symmetric' model was proposed many years ago in 1979 (Figure 1) [22,23].

*Corresponding author: Kristiansen JEH, Center for Biomembrane Physics (Memphys), University of Southern Denmark, Campusvej 55, DK-5230, Odense M, Denmark, E-mail: malthe@dadlnet.dk

Received May 02, 2017; Accepted May 16, 2017; Published May 26, 2017

Citation: Kristiansen JEH, Fey SJ (2017) The Accepted "Clinical Interaction Model": A Special Case of Reality. J Bioequiv Availab 9: 418-423. doi: 10.4172/jbb.1000335

Copyright: (๑) 2017 Kristiansen JEH, et al. This is an open-access article distributed under the terms of the Creative Commons Attribution License, which permits unrestricted use, distribution, and reproduction in any medium, provided the original author and source are credited. 


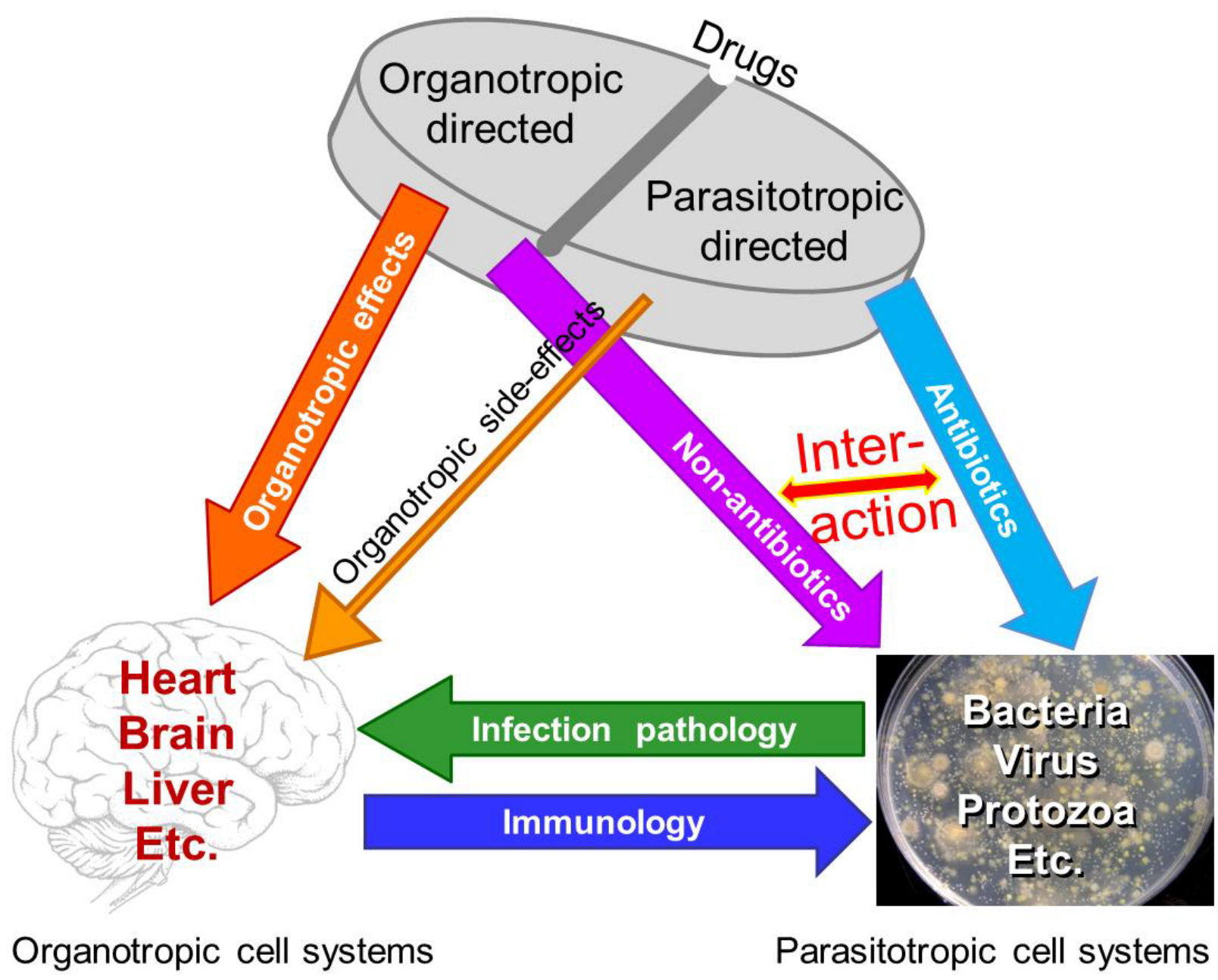

Figure 1: Interactions between drugs and organisms. Organ dysfunction is normally treated with organotropic drugs in order to restore homeostasis of the organism. These drugs will be carefully screened to eliminate as many unwanted side effects on the organism as possible. When an organism becomes infected with a pathogenic microorganism (whether bacterial, viral, protozoans or other) it will respond immunologically. This response is augmented with various types of antibiotics or chemotherapeutic drugs. These drugs will also be selected to exclude the unwanted organotropic side effects (symbolised by the thin arrow). These selection procedures therefore 'overlook' the effect of organotropic directed drugs on microorganisms. These have been called non-antibiotic effects. There may be interactions (direct or indirect) between antibiotics and non-antibiotics.

When an organism becomes infected with a pathogenic microorganism (whether bacterial, viral, protozoan or other) it will respond immunologically. This response is augmented with various types of antibiotics or chemotherapeutic drugs. These drugs will also be selected to exclude the unwanted organotropic side effects (symbolised by the thin arrow). These selection procedures therefore 'overlook' the effect of organotropic directed drugs on microorganisms. These have been called non-antibiotic effects. There may be interactions (direct or indirect) between antibiotics and non-antibiotics.

\section{Consequences of the Two-sided Effect of Psychotherapeutic Drugs and Other Non-Antibiotics}

The observation, which was initially made relating psychotherapeutics (and their stereo-isomeric analogues) with an antimicrobial effect, opens up a new paradigm in clinical microbiology and in clinical pharmacology. Exploring this paradigm raises a number of questions which can only partially be answered currently:

1) What is the significance of the two-sided effect, and the theoretical and clinical consequences of the organotropic drugs having an impact simultaneously on the organs (the host) and the microorganisms (the good and the bad bugs on/in the patient)? In other words, what is the significance, generally speaking of these non-antibiotics on the host and the microorganisms and their interaction e.g. in the infected patient? Such an activity of the non-antibiotic might be negative side effect (killing the good bugs) or positive side effects (killing the bad bugs). A few examples are known. Microorganisms have been known to be a target for phenothiazine's for many years [24].

Patients having ulcus ventriculi were treated-with trimipramine (a phenothiazine). This was used in Norway even before it was known that ulcus ventriculi was caused by a Helicobacter pylori infection $[25,26]$. 
The same two-sided activity has been seen in patients treated with chlorpromazine (a phenothiazine) for mental diseases in the beginning of the 1950's, where 'by accident' they were also cured for TB) [27-29].

Also, modern new drugs (e.g. diclophenac) used for rheumatic diseases have an unexpected antimicrobial activity and are able to cure urinary tract infections [30-32].

Diclofenac and ibuprofen have also shown distinct antibacterial activity against Enterococcus faecalis and diclofenac has shown synergistic effects with the antipsychotic trifluoperazine [33].

2) Is the non-antibiotic activity of organotropic drugs limited to the field of the psychotherapeutic group or can it be found in other classes of pharmaceutical compounds?

Intrinsically, there is no obvious reason why there should be a limitation to psychotherapeutic compounds. Thus, we should be vigilant with all compounds, irrespective if they are drugs, food additives or even normal molecules in our food or environment if they can affect either our organism or our parasites [34-36].

Antimicrobial activity has been found in many other compounds including flavanones, isoflavones and prenylflavanones [37,38]; antihistamines [39,40], antihypertensive agent methyl-L-DOPA [41]; cardiovascular drugs oxyfedrine and dobutamine [42]; local and general anaesthetics $[17,43,44]$ and barbiturates [45].

A comprehensive search for antimicrobial activity of non-antibiotic drugs, (selected from 90 different pharmaceutical products) against Staphylococcus aureus, Escherichia coli, Pseudomonas aeruginosa, Candida albicans identified numerous active compounds including paroxetine, buflomedile, bencyclane, hydroxyzine, risedronate, atomoxetine, oseltamivir, valproate, niclozamide and oxybendazol $[35,46]$. This study alone underlines the fact that the antimicrobial activity of compounds that were not developed for that purpose are not common and that this urgently needs to be taken into considerationwhether it is for treatment, as a food additive or in the environment around us. This is probably only the tip of the iceberg: many more compounds need to be investigated in future to obtain a more representative picture.

3) All organotrophic drugs have, a priori, the possibility to interact with both the organs in the host and on the microorganisms in and outside the host (the patient). Therefore, each eukaryotic-directed compound in the clinic has to be considered to be a non-antibiotic until the opposite has been demonstrated $[35,46]$.

This is currently generally not investigated during drug development but should be.

4) Non-antibiotics have the potential to interfere with natural microbial flora of the host. What is the effect on the healthy host?

While we are only just beginning to understand the importance of this microbiome, we can still only guess at the consequences of changes to it. In the light of their antimicrobial effect, these non-antibiotics would be expected to disturb the "ecological" balance. This topic has already attracted attention in the antibiotic research in $1980[47,48]$. Even food needs to be evaluated: grapefruit oil contains components which act as potential novel efflux pump modulators in methicillinresistant $S$. aureus bacterial strains [49].

5) Antibiotics and non-antibiotics can have a significant impact on the microbiota in the gut (and elsewhere in or on the organism). This will alter the nutritional content of the gut and which in turn may lead to the expansion of pathogenic (antibiotic resistant) populations [50] and lead to the development of disease [51].

Even though current studies of the correlation of antibiotic use with the development of diabetes are inconclusive [52], it becomes necessary to consider the additional influence of non-antibiotics in order to obtain a clearer picture both of the positive and negative side effects of the very different classes of non-antibiotics: pharmaceutical compounds, foods, food additives, chemicals in our environment, etc. and their possible interactions with each other or with the classical "antibiotics".

6) One of the clinically relevant consequences of inadequate regard for the prokaryotic effect of eukaryote-directed drugs might be that the beneficial effects obtained may be incorrectly ascribed. In other words, the understanding of the disease and its diagnosis and treatment may be based on a scientific or clinical fallacy.

There are reports of specially-sensitive patients who were treated with the antihistamine (and neuroleptic) trimipramine for their irritable bowel syndrome. Their cure was not, as believed for the disease, but in reality, for their Helicobacter infection in the stomach (see discussion above $[25,26])$. This raises the questions of how many unknown (mental) diseases are infections and how many patients are "treated lifelong with neuroleptics" for unknown zoonosis and infections?

7) Often organotrophic compounds are prescribed together with classical antibiotics/ chemotherapeutics. In the patient, the pharmacological response might be synergistic/ antagonistic or no interaction on the natural/pathogen microorganisms and the immunesystem.

In a recent study, the combined action of dicloxacillin (DCX) in combination with thioridazine (TDZ) was found to be toxic in a normal porcine model for catheter-carried Staphylococcus aureus infections. Reduction of the dose of both revealed a synergistic activity between the antibiotic and the non-antibiotic [53]. Similar synergistic effects have been observed between thioridazine in combination with antibiotics for treating extensively drug-resistant infections of pulmonary tuberculosis [54,55].

These possibilities for active utilization of the antimicrobial potency of non-antibiotic have opened a new pharmacological world and several new possibilities for treating especially infections that we,

\section{Perspective}

Can antibiotic resistance be reversed?

Can pathogenicity and virulence be reduced by means of psychotherapeutics and/or other non-antibiotics and their analogues?

Can the synergy between psychotherapeutics and "classical" antibiotics/chemotherapeutics be expoited (for example to reduce the dose)?

Can new antibiotics be developed from the already known non-antibiotics

Can "purer" drugs be developed by utilizing stereo-specificity? Up until $1985,85 \%$ of all drugs were mixtures

Expectation

References

Yes $\quad[39,40,55-61]$

Yes

Will this polypharmacy have any influence on the pharmacokinetics or pharmacodynamics of clinical treatment for the patient/host

Table 1: Possibilities for active utilization of the antimicrobial activity of non-antibiotics are listed below. 
up until now, have not been able to treat. The demonstration of the antimicrobial activity of non-antibiotics raises a number of exciting perspectives. These are illustrated in Table 1.

Poul Ehrlich was the first to note that methylene blue stained not only bacteria but also nervous tissue preferentially to other tissues, presumably because of their increased lipid content. There are considerable differences in the composition of membranes both between prokaryotes and eukaryotes and between different membranes in the eukaryotic cell. For example, cardiolipin is a major component in membrane domains in bacteria and mitochondria [87]. Other phospholipids are distributed in the various eukaryotic membranes in a decidedly non-random manner [88]. Since most of the non-antibiotics are lipophilic, they will naturally accumulate in membranes. Furthermore, the solubility of for example phenothiazine is different in different phospholipids [20] and therefore the effects of the non-antibiotic will be exerted locally even at the sub-cellular level. Interestingly, organism-wide proteomic studies have shown that the brain is the tissue with the second largest number of enriched proteins (318) (second only to the testis) and of these, many are low expression and membrane bound (and therefore potentially drug targets) [89]. Since it is calculated that $50 \%$ of drug targets are membrane proteins [90] (class I GPCRs (45\%), nuclear receptors (2\%), ligand-gated and voltage gated ion channels (5\%) [91] while soluble proteins like enzymes constitute $29-50 \%$ [92-94] it is perhaps not so surprising that non-antibiotics can also influence neurological signalling and cell communication.

It would therefore be relevant to carry out a comparative scientific study of the frequency of infections, the bacterial flora and their resistance characteristics in patients. Perhaps this could be effectively carried out using psychiatric patients under long-term treatment with psychopharmacological drugs (especially those treated with phenothiazines, thioxanthenes or phenylpiperidines which have been shown to have non-antibiotic activities) [23].

In this discussion, we hope that we have illustrated that the clinical interaction is much more complex than generally taken into account. For the same reasons, the development of antibiotic resistance is equally complex-and the simple cessation of the use of antibiotics would not lead to the recovery of antibiotic sensitive microorganisms. In order to understand the complexity of resistance it will be necessary to investigate and include the many different parameters important also for the general resistance development-as illustrated in this biologically 'symmetric' model [95].

\section{Conclusion}

There is a need for a general theory which describes interactions between the host organism, microorganisms and compounds (including drugs, pharmacological compounds and compounds which are chemically foreign or hostile to a biological system).

Thus, we are now able to fill more and more compounds into the gap described in the general model were the parasitotropic activity of organotropic drugs (non-antibiotics) earlier was totally neglected.

Previously, its importance was estimated to be zero in a mathematical model. A revision of the mathematical model to describe the influence of non-antibiotics in real life will result in a general theory of the interplay between host organism, microorganisms and drugs. These interactions may be ether synergistic (positive e.g. inhibit resistance development even up to reversal of resistance by boosting antimicrobial activities of classical antibiotic/chemotherapeutics), indifference, or antagonistic (negative: support pathogen growth, resistance development or interfere negative with the classical antibiotics/chemotherapeutics) as suggested already in 1979 [21-23,96]. The mathematical model will also have to include revisions to the ADME and to PK/PD considerations, resulting from the modified nutritional status in the gut.

Thus, the zero activity of non-antibiotics is a special case of the reality in the clinical pharmacology.

The instatement of non-antibiotics allows us to develop pharmacology into a general description of reality which encompasses both the 'overlooked organ' (the 'parasites' in and on us) and the compounds which affect them.

\section{Acknowledgments}

We would like to acknowledge the strong support of cand. econ. Thorkild Kristiansen in the development of this hypothesis. We would also like to acknowledge the support of the members of the COST action 1407 "Challenging organic syntheses inspired by nature-from natural products chemistry to drug discovery" for fruitful discussions. This manuscript is dedicated to Thorkild Kristiansen for his ceaseless help and encouragement.

\section{References}

1. Fischer E (1894) Einfluss der Configuration auf die Wirkung der Enzyme Berichte der Deutschen Chemischen Gesellschaft 27: 2985-2993.

2. Kell DB (2013) Finding novel pharmaceuticals in the systems biology era using multiple effective drug targets, phenotypic screening and knowledge of transporters: where drug discovery went wrong and how to fix it. FEBS J 280: 5957-5980.

3. Margineanu DG (2014) Systems biology, complexity, and the impact on antiepileptic drug discovery. Epilepsy Behav 38: 131-142.

4. Dias KS, Viegas C (2014) Multi-Target directed drugs: a modern approach for design of new drugs for the treatment of Alzheimer's disease.. Curr Neuropharmacol 12: 239-255.

5. Zheng H, Fridkin M, Youdim M (2014) From single target to multitarget/network therapeutics in Alzheimer's therapy. Pharmaceuticals (Basel) 7: 113-135.

6. Ganesan A (2016) Multitarget drugs: an epigenetic epiphany. ChemMedChem 11: $1227-1241$

7. Karuppagounder V, Arumugam S, Giridharan VV, Sreedhar R, Bose RJ, et al (2017) Tiny molecule, big power: Multi-target approach for curcumin in diabetic cardiomyopathy. Nutrition 34: 47-54.

8. Tremlett H, Bauer KC, Appel-Cresswell S, Finlay BB, Waubant E (2017) The gut microbiome in human neurological disease: A review. Ann Neurol 81: 369-382.

9. Enright EF, Gahan CG, Joyce SA, Griffin BT (2016) The Impact of the Gut Microbiota on Drug Metabolism and Clinical Outcome. Yale J Biol Med 89: 375-382.

10. Patterson E, Ryan PM, Cryan JF, Dinan TG, Ross RP, et al. (2015) Gut microbiota, obesity and diabetes. Postgrad Med J 92: 286-300.

11. Vuong HE, Yano JM, Fung TC, Hsiao EY (2017) The Microbiome and Host Behavior. Ann Rev Neurosci.

12. Ehrlich P, Leppmann A (1890) Ueber schmerzstillende Wirkung des Methylenblau. Deutsche Medizinische Wochenschrift 16: 493-494.

13. Guttmann P, Ehrlich P (1891) Über die Wirkung des Methylenblau bei Malaria Berliner Klin Wochenschr 39: 953-956.

14. Vennerstrom JL, Makler MT, Angerhofer CK, Williams JA (1995) Antimalaria dyes revisited: xanthenes, azines, oxazines, and thiazines. Antimicrob Agents Chemother 39: 2671-2677.

15. Bodoni $P$ (1899) Dell azione sedativa del bleu di metylene in varia forme $\mathrm{d}$ psicoci. Clin Med Ital XXIV: 217-222.

16. Kristiansen JE (1989) Dyes, antipsychotic drugs, and antimicrobial activity. Fragments of a development, with special reference to the influence of Paul Ehrlich. Dan Med Bull 36: 178-185.

17. Bender AB, Kristiansen JE (1999) Antimicrobial effects of anesthetics and analgesics. Ugeskrift for Laeger 161: 5814-5817. 
Citation: Kristiansen JEH, Fey SJ (2017) The Accepted "Clinical Interaction Model": A Special Case of Reality. J Bioequiv Availab 9: 418-423. doi: $10.4172 / \mathrm{jbb} .1000335$

18. Wainwright M, Amaral L, Kristiansen JE (2012) The Evolution of Antimycobacterial Agents from Non-Antibiotics. Open J Pharmacol 2: 1-11.

19. Kristiansen JE, Dastidar SG, Palchoudhuri S, Roy DS, Das S, et al. (2015) Phenothiazines as a solution for multidrug resistant tuberculosis: From the origin to present. Int Microbiol 18: 1-12.

20. Keyzer H, Fey SJ, Thornton B, Kristiansen JE (2015) Molar ratios of therapeutic water-soluble phenothiazine $\cdot$ water-insoluble phospholipid adducts reveal a Fibonacci correlation and a putative link for structure-activity relationships. Rsc Adv 5: 20865-20877.

21. Kristiansen JE (1992) The antimicrobial activity of non-antibiotics. Report from a congress on the antimicrobial effect of drugs other than antibiotics on bacteria, viruses, protozoa, and other organisms. APMIS 30: 7-14

22. Kristiansen JE (1979) Experiments to illustrate the effect of chlorpromazine on the permeability of the bacterial cell wall. Acta Pathol Microbiol Scand B 87: $317-319$

23. Kristiansen JE (1990) The antimicrobial activity of psychotherapeutic drugs and stereo-isomeric analogues. Dan Med Bull 37: 165-182.

24. Forrest IS, Quesada F, Deitchman GL (1964) Unicellular organisms as model systems for the mode of action of phenothiazine and related drugs. Proc West Pharmacol Soc 7: 42-44.

25. Kristiansen JE, Justesen T, Hvidberg EF, Andersen LP (1989) Trimipramine and other antipsychotics inhibit Campylobacter pylori in vitro. Pharmacol Toxicol 64: 386-388

26. Myren J, Lovland B, Larssen SE, Larsen S (1984) A double-blind study of the effect of trimipramine in patients with the irritable bowel syndrome. Scand $J$ Gastroenterol 19: 835-843.

27. Geiger H, Finkelstein BA (1954) Largactil in der Behandlung der Tuberculosis. Schweizer Med Wochenschr 84: 1063-1064.

28. Alcozer G, Lingianli G (1957) La cloropromazina nella terapia della tuberculosis polmonare. Arch E Maragliano Pat Clin 13: 1247-1264.

29. Levaditi C, Chaigneau-Erhard H, Henry-Eveno J (1951) Antihistamine 3277 R.P. (phenergan) as a curative agent in experimental tuberculosis in mice. C R Seances Soc Biol Fil 145: 1454-1456.

30. Gagyor I, Bleidorn J, Kochen MM, Schmiemann G, Wegscheider K, et al. (2015) Ibuprofen versus fosfomycin for uncomplicated urinary tract infection in women: randomised controlled trial. BMJ 351: h6544.

31. Kristiansen JE (2016) Non-antibiotic effects of ibuprofen in uncomplicated urinary tract infection in women. BMJ 352: $i 1171$.

32. Salem-Milani A, Balaei-Gajan E, Rahimi S, Moosavi Z, Abdollahi A, et al. (2013) Antibacterial Effect of Diclofenac Sodium on Enterococcus faecalis. J Dent (Tehran) 10: 16-22.

33. Dastidar SG, Annadurai S, Kumar KA, Dutta NK, Chakrabarty AN (2003) Evaluation of a synergistic combination between the non-antibiotic microbicides diclofenac and trifluoperazine. Int J Antimicrob Agents 21: 599-601.

34. Russell AD (1991) Mechanisms of bacterial resistance to non-antibiotics: food additives and food and pharmaceutical preservatives. J Appl Bacteriol 71: 191-201.

35. Bocian E, Grzybowska W, Tyski S (2014) Evaluation of mycobactericidal activity of selected chemical disinfectants and antiseptics according to European standards. Med Sci Monit 20: 666-673.

36. Denyer SP, Hodges NA, Gorman SP, Gilmore BF (2011) Hugo and Russell's Pharmaceutical Microbiology ( $8^{\text {th }}$ edn.). Wiley-Blackwell Science Ltd., USA p: 456.

37. Dastidar SG, Mahapatra SK, Ganguly K, Chakrabarty AN, Shirataki Y, et al. (2001) Antimicrobial activity of prenylflavanones. In Vivo 15: 519-523.

38. Dastidar SG, Manna A, Kumar KA, Mazumdar K, Dutta NK, et al. (2004) Studies on the antibacterial potentiality of isoflavones. Int J Antimicrob Agents 23: 99-102.

39. Perlmutter JI, Forbes LT, Krysan DJ, Ebsworth-Mojica K, Colquhoun JM, et al. (2005) Repurposing the antihistamine terfenadine for antimicrobial activity against Staphylococcus aureus. J Med Chem 57: 8540-8562.

40. El-Nakeeb MA, Abou-Shleib HM, Khali AM, Omar HG, El-Halfawy OM (2012) Reversal of antibiotic resistance in Gram-positive bacteria by the antihistaminic azelastine. APMIS 120: 215-220.
41. Dutta NK, Mazumdar K, Dastidar SG, Chakrabarty AN, Shirataki Y, et al. (2005) In vitro and in vivo antimycobacterial activity of an antihypertensive agent methyl-L-DOPA. In Vivo 19: 539-545.

42. Mazumdar K, Ganguly K, Kumar KA, Dutta NK, Chakrabarty AN, et al. (2003) Antimicrobial potentiality of a new non-antibiotic: the cardiovascular drug oxyfedrine hydrochloride. Microbiol Res 158: 259-264.

43. Sakuragi T, Yanagisawa K, Shirai Y, Dan K (1999) Growth of Escherichia coli in propofol, lidocaine, and mixtures of propofol and lidocaine. Acta Anaesthesiol Scand 43: 476-479.

44. Marvalin C, Denoux M, Perard S, Roy S, Azerad R (2012) Microbial production of phase I and phase II metabolites of midazolam. Xenobiotica 42: 285-293.

45. Jeong YC, Moloney MG (2005) Antibacterial barbituric acid analogues inspired from natural 3-acyltetramic acids; synthesis, tautomerism and structure and physicochemical property-antibacterial activity relationships. Molecules 20 : 3582-3627.

46. Kruszewska H, Zareba T, Tyski S (2012) Examination of antimicrobial activity of selected non-antibiotic medicinal preparations. Acta Pol Pharm 69: 1368-1371.

47. Ray S, Dastidar SG, Chakrabarty AN (1980) Antibiotic cross-resistance patterns of ambodryl and promazine resistant mutants. Br J Exp Pathol 61: 465-470.

48. Pruul H, McDonald PJ (1988) Damage to bacteria by antibiotics in vitro and its relevance to antimicrobial chemotherapy: a historical perspective. J Antimicrob Chemother 21: 695-698.

49. Abulrob AN, Suller MT, Gumbleton M, Simons C, Russell AD (2004) Identification and biological evaluation of grapefruit oil components as potential novel efflux pump modulators in methicillin-resistant Staphylococcus aureus bacterial strains. Phytochemistry 65: 3021-3027.

50. Baumler AJ, Sperandio V (2016) Interactions between the microbiota and pathogenic bacteria in the gut. Nature 535: 85-93.

51. Principi N, Esposito S (2016) Antibiotic administration and the development of obesity in children. Int J Antimicrob Agents 47: 171-177.

52. Mikkelsen KH, Allin KH, Knop FK (2016) Effect of antibiotics on gut microbiota, glucose metabolism and body weight regulation: a review of the literature. Diabetes Obes Metab 18: 444-453.

53. Stenger M, Klein K, Gronnemose RB, Klitgaard JK, Kolmos HJ, et al. (2016) Co-release of dicloxacillin and thioridazine from catheter material containing an interpenetrating polymer network for inhibiting device-associated Staphylococcus aureus infection. J Control Release 241: 125-134.

54. Amaral L, Molnar J (2014) Mechanisms by which thioridazine in combination with antibiotics cures extensively drug-resistant infections of pulmonary tuberculosis. In Vivo 28: 267-271.

55. Abbate E, Vescovo M, Natiello M, Cufre M, Garcia A, et al. (2012) Successful alternative treatment of extensively drug-resistant tuberculosis in Argentina with a combination of linezolid, moxifloxacin and thioridazine. J Antimicrob Chemother 67: 473-477.

56. Hendricks $O$, Poulsen MØ, Kristiansen JE (2014) Antibacterial synergy between JEK 47 and oxacillin in a murine model of MRSA. SEEC, 5th Conference on Chemotherapy \& Infection, Slovenia.

57. Poulsen MØ (2004) Antimicrobial effect of chosen non-antibiotics on Helicobacter pylori and their potential to reverse antibiotic resistance, in vitro. University of Southern Denmark, Denmark.

58. Kristiansen JE, Hendricks O, Delvin T, Butterworth TS, Aagaard L, et al. (2007) Reversal of resistance in microorganisms by help of non-antibiotics. $J$ Antimicrob Chemother 59: 1271-1279.

59. Kristiansen JE, Thomsen VF, Martins A, Viveiros M, Amaral L (2010) Nonantibiotics reverse resistance of bacteria to antibiotics. In Vivo 24: 751-754.

60. Stenger M, Hendel K, Bollen P, Licht PB, Kolmos HJ, et al. (2015) Assessments of thioridazine as a helper compound to dicloxacillin against methicillin-resistant Staphylococcus aureus: In vivo trials in a mouse peritonitis model. PloS ONE 10: $\mathrm{e} 0135571$.

61. Martin SK, Oduola AM, Milhous WK (1987) Reversal of chloroquine resistance in Plasmodium falciparum by verapamil. Science 235: 899-901.

62. Musuka S, Srivastava S, Dona CWS, Meek C, Leff R, et al. (2013) Thioridazine pharmacokinetic-pharmacodynamic parameters "Wobble" during treatment of 
Citation: Kristiansen JEH, Fey SJ (2017) The Accepted "Clinical Interaction Model": A Special Case of Reality. J Bioequiv Availab 9: 418-423. doi: $10.4172 / \mathrm{jbb} .1000335$

tuberculosis: a theoretical basis for shorter-duration curative monotherapy with congeners. Antimicrob Agents Chemother 57: 5870-5877.

63. Dutta NK, Pinn ML, Karakousis PC (2014) Reduced emergence of isoniazid resistance with concurrent use of thioridazine against acute murine tuberculosis. Antimicrob Agents Chemother 58: 4048-4053.

64. Schirmer RH, Adler H, Pickhardt M, Mandelkow E (2011) "Lest we forget youmethylene blue." Neurobiol Aging 32: 2325e7-2325e16.

65. Munoz-Bellido JL, Munoz-Criado S, Garcia-Rodriguez JA (2000) Antimicrobial activity of psychotropic drugs: selective serotonin reuptake inhibitors. Int $\mathrm{J}$ Antimicrob Agents 14: 177-180.

66. Nigam A, Gupta D, Sharma A (2014) Treatment of infectious disease: beyond antibiotics. Microbiol Res 169: 643-651.

67. Kristiansen JE, Sebbesen O, Frimodt-Moller N, Aaes-Jorgensen T, Hvidberg EF (1988) Synergy between a non-neuroleptic thioxanthene stereo-isomer and penicillin in vivo. APMIS 96: 1079-1084.

68. Rasmussen KS, Poulsen MO, Jacobsen K, Skov MN, Kolmos HJ, et al. (2017) Combination of thioridazine and dicloxacillin as a possible treatment strategy of Staphylococci. New Microbiol 40.

69. Ramon-Garcia S, Ng C, Anderson H, Chao JD, Zheng X, et al. (2011) Synergistic drug combinations for tuberculosis therapy identified by a novel high-throughput screen. Antimicrob Agents Chemother 55: 3861-3869.

70. Gravem A, Bugge A (1981) Cis(Z)-clopenthixol and clopenthixol in the treatment of acute psychoses and exacerbations of chronic psychoses. A double-blind clinical investigation. Acta Psychiatr Scand 294: 13-24.

71. Nutt DJ, Feetam CL (2010) What one hand giveth the other taketh away: some unpredicted effects of enantiomers in psychopharmacology. J Psychopharmacol 24: $1137-1141$

72. Ohlow MJ, Moosmann B (2011) Phenothiazine: the seven lives of pharmacology's first lead structure. Drug Discov Today 16: 119-131.

73. Thanacoody HK (2007) Thioridazine: resurrection as an antimicrobial agent? $\mathrm{Br}$ J Clin Pharmacol 64: 566-574.

74. Thanacoody RH (2011) Thioridazine: the good and the bad. Recent patents on anti-infective drug discovery.

75. Ariens EJ (1984) Stereochemistry, a basis for sophisticated nonsense in pharmacokinetics and clinical pharmacology. Eur J Clin Pharmacol 26: 663-668.

76. Nolen WA (1983) Dopamine and mania. The effects of trans- and cisclopenthixol in a double-blind pilot study. J Affect Disord 5: 91-96.

77. Höschl C, Svestka J (2008) Escitalopram for the treatment of major depression and anxiety disorders. Expert Rev Neurother 8: 537-552.

78. Konig P, Seifert T, Eberhardt G (1986) Findings with cis-Z-clopenthixol in the treatment of acute mania and schizophrenia. Pharmacopsychiatry 19: 424-428.

79. Williams JD (1995) The Garrod Lecture: Selective toxicity and concordant pharmacodynamics of antibiotics and other drugs. J Antimicrob Chemother 35 : 721-737.
80. Wojcikowski J, Haduch A, Daniel WA (2012) Effect of classic and atypica neuroleptics on cytochrome P450 3A (CYP3A) in rat liver. Pharmacol Rep 64: 1411-1418.

81. Noreddin AM, El-Khatib W, Haynes V (2008) Optimal dosing design for antibiotic therapy in the elderly: a pharmacokinetic and pharmacodynamic perspective. Recent Pat Antiinfect Drug Discov 3: 45-52.

82. Hu M, Zheng C, Gao F (2016) Use of bedaquiline and delamanid in diabetes patients: clinical and pharmacological considerations. Drug Des Devel Ther 10 3983-3994.

83. Paulzen M, Haen E, Hiemke C, Stegmann B, Lammertz SE, et al. (2017) Cytochrome $\mathrm{P} 450$-mediated interaction between perazine and risperidone: implications for antipsychotic polypharmacy. $\mathrm{Br} \mathrm{J}$ Clin Pharmacol.

84. Martinez JL, Baquero F (2014) Emergence and spread of antibiotic resistance: setting a parameter space. Ups J Med Sci 119: 68-77.

85. Vandevelde NM, Tulkens PM, Van Bambeke F (2016) Modulating antibiotic activity towards respiratory bacterial pathogens by co-medications: a multitarget approach. Drug Discov Today 21: 1114-1129.

86. Veje C, Willatzen M, Hendricks O, Pages JM, Kristiansen JE (2012) Population Dynamics Approach for the Study of Synergetic Coupling between Antibiotic and Helper Compounds. Comput Mol Biosci 2: 1-6.

87. Mileykovskaya E, Dowhan W (2009) Cardiolipin membrane domains in prokaryotes and eukaryotes. Biochimica et Biophysica Acta 1788: 2084-2091.

88. van Meer G, Voelker DR, Feigenson GW (2008) Membrane lipids: where they are and how they behave. Nat Rev Mol Cell Biol 9: 112-124.

89. Uhlen M, Fagerberg L, Hallstrom BM, Lindskog C, Oksvold P, et al. (2015) Proteomics tissue-based map of the human proteome. Science 347: 1260419.

90. Adams R, Worth CL, Guenther S, Dunkel M, Lehmann R, et al. (2012) Binding sites in membrane proteins-diversity, druggability and prospects. Eur $\mathrm{J}$ Cell Biol 91: 326-339.

91. Overington JP, Al-Lazikani B, Hopkins AL (2006) How many drug targets are there? Nat Rev Drug Discov 5: 993-996.

92. Rask-Andersen M, Almen MS, Schioth HB (2011) Trends in the exploitation of novel drug targets. Nat Rev Drug Discov 10: 579-590.

93. Zheng CJ, Han LY, Yap CW, Ji ZL, Cao ZW, et al. (2006) Therapeutic targets: progress of their exploration and investigation of their characteristics. Pharmacol Rev 58: 259-279.

94. Bull SC, Doig AJ (2015) Properties of protein drug target classes. PloS ONE 10: e0117955.

95. Rasmussen A (1955) Pristeori eller parameterteori-Studier omkring virksomhedens afsætning. København: Harcks forlag, p: 256.

96. Kristiansen JE (1981) Are chlorpromazine and other phenothiazines also antibiotics? Ugeskrift for Laeger 143: 1900-1904. 